\title{
THE THANKSGIVING MEETING IN LINCOLN
}

The three hundred seventeenth regular meeting of the Society was held at the University of Nebraska on Friday and Saturday, November 30-December 1, 1934. About sixty persons attended the meeting, among whom were the following twenty-nine members of the Society:

R. W. Babcock, Wealthy Babcock, M. A. Basoco, M. H. Beaty, F. L. Black, G. A. Bliss, W. C. Brenke, C. C. Camp, A. L. Candy, O. C. Collins, A. T. Craig, H. P. Doole, J. M. Earl, W. E. Ekman, M. G. Gaba, Emma Hyde, M. H. Ingraham, A. J. Kempner, H. I. Lane, U. G. Mitchell, T. A. Mossman, T. A. Pierce, B. L. Remick, D. H. Richert, L. L. Runge, E. B. Stouffer, J. S. Turner, W. G. Warnock, M. A. Wilder.

On Friday afternoon Professor A. J. Kempner of the University of Colorado gave an address entitled On complex roots of algebraic equations. On Saturday morning Professor G. A. Bliss of the University of Chicago spoke to the Society on The problem of Bolza in the calculus of variations.

On Friday evening a dinner was held at the Hotel Cornhusker. Thirty-nine mathematicians and their guests attended. Professor M. G. Gaba of the University of Nebraska acted as toastmaster, and he first called upon Professor W. C. Brenke who welcomed the visitors to the University of Nebraska. Professor Bliss was then called upon and he spoke concerning various recent experiments in education. Professor M. H. Ingraham of the University of Wisconsin talked on the action which had been taken at Wisconsin regarding mathematics as an entrance requirement. Dean E. B. Stouffer of the University of Kansas then spoke on the work of the committee of the Mathematical Association which is making a study of the training of teachers for college work and certain problems which might be best solved by a modification of the present work for the doctor's degree. Dean R. W. Babcock of Kansas State College pointed out the value of the smaller meetings of the Society which allow members living farther away from the places of frequent meetings to meet each other and talk about mathematics. Professor Kempner discussed the problems which have arisen from the rating by a national committee of various 
universities as to their qualifications for giving the training leading to a doctor's degree.

Professors Brenke and Bliss presided at the meeting on Friday afternoon, and Professors Stouffer and Kempner presided on Saturday morning.

The titles of papers read at the meeting follow. Those whose abstract numbers are followed by $t$ were read by title. Mr. Cowgill was introduced by Professor Brenke, Miss Humphreys and Mr. Ghent by Professor Dickson, Dr. Robertson by Professor Bliss, Dr. Anderson by Professor Holl, and Mr. Harper by Professor Rietz.

1. On the summability of a class of series of Jacobi polynomials, by Mr. A. P. Cowgill. (Abstract No. 40-11-362.)

2. On certain systems of polynomials, by Professor M. A. Basoco. (Abstract No. 40-11-367.)

3. Arithmetized expansions for certain pseudo-periodic functions, by Professor M. A. Basoco. (Abstract No. 40-11-369.)

4. A generalization of Chevilliet's formula, by Professor C. C. Camp. (Abstract No. 40-11-364.)

5. Note on numerical evaluation of double series, by Professor C. C. Camp. (Abstract No. 40-11-365.)

6. Involutorial simple algebras and real Riemann matrices, by Professor A. A. Albert. (Abstract No. 40-11-363-t.)

7. The representation of integers as sums of values of quartic polynomials (preliminary report), by Miss M. G. Humphreys. (Abstract No. 40-11-310-t.)

8. Operational identities on point sets, by Mr. Garrett Birkhoff. (Abstract No. 40-11-337-t.)

9. The arithmetized expansions for certain doubly periodic functions of the third kind, by Mr. G. D. Nichols. (Abstract No. 40-11-358-t.)

10. A generalization of Waring's theorem (preliminary report), by Mr. K. S. Ghent. (Abstract No. 40-11-359-t.)

11. Stieltjes integral for functions convex in one direction, by Dr. M. S. Robertson (National Research Fellow). (Abstract No. 40-11-360-t.)

12. On a certain identity due to Hermite, by Professor M. A. Basoco. (Abstract No. 40-11-368-t.)

13. Further theta expansions useful in arithmetic, by Professor 
M. A. Basoco and Professor E. T. Bell. (Abstract No. 40-11370-t.)

14. Linear derivative inequalities, by Professor H. J. Ettlinger. (Abstract No. 40-11-355-t.)

15. On the Bernoulli distribution, by Dr. Solomon Kullback. (Abstract No. 40-11-338-t.)

16. On the multinomial distribution, by Dr. Solomon Kullback. (Abstract No. 40-11-357-t.)

17. Statics of special types of homogeneous elastic slabs with variable thickness, by Dr. E. W. Anderson. (Abstract No. 4011-371-t.)

18. On the distribution of a certain product moment, by Professor A. T. Craig. (Abstract No. 40-11-361.)

19. On a function to represent infantile mortality, by Mr. F. S. Harper. (Abstract No. 40-11-356.)

20. Finite geometries (preliminary report), by Professor M. G. Gaba. (Abstract No. 40-11-366.)

M. H. InGRAHAM, Associate Secretary 